\title{
Jürg Stöcklin · Markus Fischer \\ Plants with longer-lived seeds have lower local extinction rates in grassland remnants 1950-1985
}

Received: 23 December 1998 / Accepted: 29 May 1999

\begin{abstract}
We investigated whether plant species with longer-lived seeds in the soil had lower rates of local extinction between 1950 and 1985 than species with shorter-lived seeds in 26 intact remnants of extensively used calcareous grasslands. In a previous study we had found higher rates of local extinction for smaller populations, for species with shorter life cycles, and for species with higher habitat specificity. We compiled information on seed longevity from recent literature. Seed longevity had a highly significant effect on the rate of population extinction. Rates of local extinction were lower for species with seed longevity $>5$ years $(33.8 \%$; 31 species) compared with species with shorter-lived seeds (1-5 years: $60.7 \%$, 46 species; $<1$ year: $58.5 \%, 81$ species). The integration of seed longevity into our analysis did not change our previous conclusions on the dependence of local extinction rates on habitat specificity and on life form. Species in our data set with higher habitat specificity tended to have shorter-lived seeds than species with lower habitat specificity. Thus, most characteristic species of calcareous grassland do not persist in the seed bank and can not rely on this mechanism as a buffer against local extinction.
\end{abstract}

Key words Calcareous grassland - Conservation . Local extinction $\cdot$ Seed bank $\cdot$ Seed longevity

\section{Introduction}

Because of changes in land use many formerly common, extensively used grassland habitats have become rather

J. Stöcklin $(\bowtie)$

Botanisches Institut der Universität Basel,

Schönbeinstr. 6,

CH-4056 Basel, Switzerland

e-mail: stoecklin2@ubaclu.unibas.ch, Fax: +41-61-2673504

M. Fischer

Institut für Umweltwissenschaften, Universität Zürich,

Winterthurerstr. 190,

CH-8057 Zürich, Switzerland small and isolated (Willems 1982; Ratcliffe 1984; Zoller et al. 1986). Persistence of many species therefore now depends on population persistence in such remnants. If landscape-scale processes (such as wildfire) are interrupted by fragmentation, vegetation change may be quick and species loss particularly severe (Leach and Givnish 1996). However, even if habitat quality is intact persistence of local populations is at risk because of stochastic processes including environmental fluctuations and natural catastrophes, demographic fluctuations, and loss of genetic variability (Shaffer 1987; Menges 1991, 1992; Ellstrand and Elam 1993). Of these, environmental stochasticity is currently regarded as most detrimental for population persistence (Menges 1991, 1992).

The risk of local extinction may differ among species and among populations (Pimm et al. 1988; Menges 1991). Generally, larger populations are expected to be at a lower risk of local extinction than smaller populations (Pimm et al. 1988; Simberloff 1988). Moreover, several species characteristics may affect local extinction risk. Populations of habitat specialists are more distant from each other than populations of habitat generalists. This greater isolation may reduce both population viability (Groom 1998) and probability of recolonization by migration of seeds (Fahrig and Merriam 1985; Menges 1990). Long life span of plants is considered to be a buffer against extinction risk caused by stochastic processes because it might enable populations to survive even a number of unfavourable years. Similarly, plant species with longer-lived seeds should have lower rates of local extinction than plants with shorter-lived seeds. In this way, a persistent seed bank may allow population persistence after local disappearance from the aboveground community (Poschlod 1993; Poschlod and Jackel 1993; Bakker et al. 1996; Bekker et al. 1997).

In grassland dispersal and regeneration by seed is likely to limit diversity (Grubb 1977; Tilman 1997), and the longevity of seeds in the soil might be an important species trait for maintaining diversity. Seed longevity need not to be independent of plant life span and habitat 
specificity. In the North-West European flora shorterlived species generally have longer-lived seeds and vice versa (Thompson et al. 1998). Plants typical of communities of extensively used calcareous grasslands are generally considered not to develop persistent seed banks (Hutchings and Booth 1996; Poschlod et al. 1996; Bekker et al. 1998; Davies and Waite 1998). Such correlations may make clearcut conclusions on the separate effects of plant life span, seed longevity, and habitat specificity on local extinction rates difficult.

In a previous study of local extinctions of plant populations in 26 intact remnants of extensively used and nutrient-poor calcareous grassland ("Mesobromion") in the Swiss Jura mountains over a period of about 35 years (Fischer and Stöcklin 1997), we found that rates of population extinction were higher for smaller populations than for larger populations, for species with shorter lifecycles than with longer life-cycles and higher for species with high habitat specificity than with lower habitat specificity. These results were in line with expectations derived from considerations of environmental stochasticity.

Recently information on seed longevity has become available for 158 out of 185 species $(85 \%)$ in our data set (Poschlod et al. 1996 and references therein; database in Thompson et al. 1997). This allows us to test whether species with longer-lived seeds in the soil had lower rates of local extinction than species with shorter-lived seeds. Using statistical models with several factors allows us to control for effects of several species traits possibly confounded with seed longevity, though it does not explicitly control for phylogenetic effects (Mazer 1998). In a comparative study Thompson et al. (1998) found more than $50 \%$ variance in seed longevity at the among-species level and less than $50 \%$ at higher taxonomic levels, suggesting that seed longevity is not strongly constrained by phylogeny but rather easily modified by natural selection. Nevertheless, seed persistence in the soil may not be completely independent of phylogeny and therefore we also use phylogenetically independent contrasts for an additional test of the relationship between seed longevity and extinction rate (as advocated in Harvey and Pagel 1991; Harvey et al. 1995; Silvertown et al. 1997; but see also Westoby et al. 1995; Mazer 1998).

In our previous study we detected a very important effect of population size on local extinction rates even after variation among species had been taken into account. Therefore, this result is not affected by the use of seed longevity to explain variation among species. However, we investigated whether the consideration of seed longevity changed our earlier conclusions on the effect of life form and habitat specificity on rates of local extinction.

\section{Methods}

Vegetation records $1950-1985$

We used the same pairs of new and old phytosociological vegetation records as in Fischer and Stöcklin (1997), which had been taken in 26 nutrient-poor calcareous grassland sites in the Swiss Jura mountains around 1950 and which had been repeated around 1985. Land use in these remnants had not changed between 1950 and 1985, floristic composition of old and new records was typical of Mesobromion vegetation in the Swiss Jura Mountains, and old and new records were taken approximately at the same location (for details on calcareous grassland vegetation, selection of sites, method of vegetation records, and consideration of the possibility of species pseudo-turnover see Fischer and Stöcklin 1997). Each population was represented by a species-by-abundance record in 1950. Local extinctions were considered to be those cases when a population recorded around 1950 was missing in the corresponding new record around 1985 .

Site and species properties

We tested the dependence of local extinctions on several site and species properties, and on population size. As a measure of population size we used the local abundance of a species estimated in seven classes of ground cover in 1950. Site properties were: (1) difference in mean nutrient-indicator value between vegetation records in 1950 and 1985 (values for each species were taken from Landolt 1977); (2) land use classified as meadow, pasture, or mixed use; and (3) type of phytosociological association of the Mesobromion (three distinct classes). Species properties were: (1) life form in three classes of increasing life span (i.e. species with high turnover in their life cycle (annuals and biennials), perennial species, and clonal species with pronounced vegetative colonizing ability); (2) "no", "low" or "high" Mesobromion specificity as a combined measure of habitat specificity, isolation, and regional abundance; (3) seed longevity (three categories, see below). We discarded nutrient-indicator value (Landolt 1977) as an additional species property because it did not explain significant amounts of variation in any of our analysis. For a more detailed explanation of site and species properties (other than seed longevity) see Fischer and Stöcklin (1997).

\section{Classification of seed longevity}

We classified seed longevity in three classes. Species with seeds which persist in the soil for less than 1 year have a "transient" seed bank, between 1 and 5 years a "short-term persistent" seed bank, and for at least 5 years a "long-term persistent" seed bank. This classification emphasizes whether seeds are likely to persist in the soil after a species has disappeared from the above-ground plant community which is an important criterion in restoration ecology (Bakker et al. 1996). The classification represents a modification of the scheme proposed by Thompson and Grime (1979), is based on Bakker (1989); Bakker et al. (1991), described in Thompson (1992, 1993), and was used by Thompson et al. (1997).

Our main source for species classification was Thompson et al. (1997). If the information from different studies in this database was not consistent we used the longevity index described by Thompson et al. (1998). For calculating this index only "transient" and "persistent" records are recognized. The index can have any value from 0 (no persistent records) to 1 (all records persistent) and considered species with an index below $1 / 3$ as transient, between $1 / 3$ and $2 / 3$ as short-term persistent, and above $2 / 3$ as long-term persistent. As an additional source we used data on seed bank dynamics of calcareous grassland species compiled by Poschlod (1993); Poschlod and Jackel (1993) and summarized in Poschlod et al. (1996). These authors distinguish four types of seed longevity: $1=$ transient, $<1-2$ years; $2=$ persistent for $2-5$ years; $3=$ persistent for $6-20$ (25) years; $4=$ persistent for several decades. We considered 1 and 2 as equivalent to "transient" and "short-term persistent" respectively in the classification of Thompson et al. (1997), and we combined 3 and 4 as "long-term persistent".

In the six cases of severe contradictions between sources (transient vs. long-term persistent) we classified seeds as short-term persistent. In the 19 cases of further contradictions between sources 
of information we gave priority to Thompson et al. (1997) if several studies were included in this database, otherwise we gave priority to the information indicating longer seed life-span.

The very small seeds of orchid species are never found in soil seed banks. Consequently, and following Poschlod and Jackel (1993) and R.M. Bekker (personal communication) we classified the seeds of the 17 orchid species in our data set as transient. Thus we were able to classify seed longevity of 158 out of 185 species in our data set.

\section{Statistical analysis}

We analysed the fate of 1024 populations of 158 species present in the 26 sites around 1950 (Fischer and Stöcklin 1997: 1181 populations from 185 species). The data set was analysed in two different ways, either analysing the presence or absence in vegetation records in 1985 using analysis of deviance (Payne et al. 1993) using the complementary-log-log link (Candy 1986), or performing phylogenetically independent contrasts.

The analysis of deviance contained three parts, one for sites, one for species and one for populations (see Table 1 in Fischer and Stöcklin 1997). The deviances approximately follow the $\chi^{2}$-distribution (McCullagh and Nelder 1989). Because of the hierarchical design of the model, only the effects of the sources site, species, and abundance could be tested directly by looking up the deviance change in a $\chi^{2}$ table. To avoid pseudoreplication we calculated mean deviance ratios with mean deviance of site and species as denominator (which approximately follow the $F$-distribution, quasi- $F$ values; Payne et al. 1993) for the other sources of variation.

Reduction of the data set from 185 to 158 species (1181 to 1024 populations) did not essentially change our earlier results, and all levels of significance (Table 4 in Fischer and Stöcklin 1997) remained unchanged, except for the one of life form which improved from $5 \%$ to $1 \%$ ). Then we included seed longevity as an additional explanatory parameter for variation among species into the model. Statistical significance of seed longevity did not depend on the sequence of source variables. Because none of the two- or three-wayinteractions between life form, Mesobromion specificity and seed longevity was significant, we omitted interactions from the model. To test whether the effect of seed longevity depended on the classification of orchids we also analysed a reduced data set where we omitted all orchid records (leaving 948 populations of 141 species).

Out of the 114 different genera in our data set 85 were represented by only one species and 29 by two or more species. Seven of these genera contained both species with a long-term persistent seed bank and species with shorter-lived seeds. If several species within a genus fulfilled this criterion we chosed the species pair with the highest number of occurrences in the vegetation records of 1950 . Then we used a $\chi^{2}$-test for phylogenetically independent contrasts testing the hypothesis that within these seven genera the species with a "long-term persistent" seed bank had a lower extinction rate compared with the species with shorter-lived seeds.

\section{Results}

In our data set life span of a species (high turnover $<$ perennial $<$ vegetative colonizing) was independent of seed longevity $\left(n=158 ; r_{\mathrm{S}}=-0.027, P=0.73\right.$; Table 1). Species with higher Mesobromion specificity tended to have shorter-lived seeds than species with lower specificity $\left(r_{\mathrm{S}}=-0.136, P<0.09\right.$; Table 2$)$. Mesobromion specificity was not significantly associated with life form $\left(r_{\mathrm{S}}=0.084, P=0.30\right.$; Table 3$)$.

Seed longevity had a significant effect on the rate of population extinction $(P<0.001$; Table 4$)$. Rates of local extinction were lower for species with seed longevity $>5$ years (31 species: mean $\pm \mathrm{SE}=33.8 \pm 6.1 \%$ ) compared with species with shorter-lived seeds (1-5 years: 46 species, $60.7 \pm 5.0 \%$; $<1$ year: 81 species, $58.5 \pm 3.8 \%$; Fig. 1). When we omitted orchid records (76 populations of 17 species) this pattern was conserved (with $P<0.01$ instead of 0.001 ).

Integration of seed longevity into our analysis did not change the level of significance of the effects of life form and Mesobromion specificity on local extinction. Local extinction rate was lower for vegetative colonizing species (21 species; mean $\pm \mathrm{SE}=29.8 \pm 7.4 \%$ ) than for perennial (121 species; $56.7 \pm 3.1 \%$ ) or high-turnover species (16 species, $68.2 \pm 8.5 \%$ ). Local extinction rate was higher for species with high (27 species, $69.0 \pm 6.6 \%)$ than for species with low (72 species, $49.4 \% \pm 4.0 \%$ ) or without (59 species; $53.6 \pm 4.5 \%$ ) Mesobromion specificity.

In six of seven phylogenetically independent species pairs species with a long-term persistent seed bank had a lower extinction rate compared with species with shorter lived seeds $\left(\chi^{2}=7.14, P<0.01\right)$.

\section{Discussion}

Extinction events in intact habitat remnants were significantly less frequent for species with a long-term persistent seed bank (Table 4, Fig. 1) than for species

Table 1 Relationship between the classification into classes of life form and seed longevity for 158 plant species of extensively used calcareous grasslands

\begin{tabular}{llcc}
\hline Life form & \multicolumn{3}{l}{$\begin{array}{l}\text { Number of species in class of seed } \\
\text { longevity }\end{array}$} \\
\cline { 2 - 4 } & $<1$ year & $1-5$ years & $>5$ years \\
\hline Vegetative colonizing & 6 & 9 & 6 \\
Perennial & 71 & 29 & 21 \\
High turnover & 4 & 8 & 4 \\
\hline
\end{tabular}

Table 2 Relationship between the classification into classes of Mesobromion specificity and seed longevity for 158 plant species of extensively used calcareous grasslands

\begin{tabular}{llll}
\hline $\begin{array}{l}\text { Mesobromion } \\
\text { specificity }\end{array}$ & \multicolumn{2}{l}{ Number of species in class of seed longevity } \\
\cline { 2 - 4 } & $<1$ year & $1-5$ years & $>5$ years \\
\hline No & 27 & 21 & 11 \\
Low & 34 & 20 & 18 \\
High & 20 & 5 & 2 \\
\hline
\end{tabular}

Table 3 Relationship between the classification into classes of life form and seed longevity for 158 plant species of extensively used calcareous grasslands

\begin{tabular}{lccc}
\hline \multirow{2}{*}{ Life form } & \multicolumn{3}{c}{ Number of species in class of } \\
& \multicolumn{3}{c}{ Mesobromion specificity } \\
\cline { 2 - 4 } & No & Low & High \\
\hline Vegetative colonizing & 9 & 12 & 0 \\
Perennial & 44 & 53 & 24 \\
High turn-over & 6 & 7 & 3 \\
\hline
\end{tabular}


Table 4 Summary of analysis of deviance of extinctions from around 1950 to around 1985. This analysis is based on old and new vegetation records from 26 sites. Extinctions are those cases where a species had been recorded around 1950 but was absent around 1985. Out of 1024 possible extinctions 388 were observed

${ }^{a}$ Significance level of this source of variation was obtained from the $\chi^{2}$ distribution

${ }^{\mathrm{b}}$ Abundance was log-transformed prior to analysis, ns, $P>0.05$

\begin{tabular}{|c|c|c|c|c|c|}
\hline Source of variation & $d f$ & Deviance & $\begin{array}{l}\text { Mean } \\
\text { deviance }\end{array}$ & Quasi- $F$ & $P$ \\
\hline \multicolumn{6}{|l|}{ Sites } \\
\hline Difference in mean nutrient indicator value & 1 & 24.88 & 24.88 & 6.82 & $<0.05$ \\
\hline Land use (LU) & 3 & 5.49 & 1.83 & 0.50 & ns \\
\hline Phytosociological association (PA) & 2 & 4.10 & 2.05 & 0.56 & ns \\
\hline Site nested within $\mathrm{LU}$ and $\mathrm{PA}^{\mathrm{b}}$ & 19 & 69.39 & 3.65 & & $<0.001$ \\
\hline \multicolumn{6}{|l|}{ Species } \\
\hline Seed longevity (SL) & 2 & 37.12 & 18.56 & 8.55 & $<0.001$ \\
\hline Mesobromion specificity (MS) & 2 & 15.81 & 7.90 & 3.64 & $<0.05$ \\
\hline Life from $(\mathrm{LF})$ & 2 & 21.50 & 10.75 & 4.95 & $<0.01$ \\
\hline Species nested within SL, MS, and $\mathrm{LF}^{\mathrm{a}}$ & 151 & 327.79 & 2.17 & & $<0.001$ \\
\hline \multicolumn{6}{|l|}{ Populations } \\
\hline Abundance ${ }^{\mathrm{b}}$ & 1 & 7.59 & 7.59 & & $<0.01$ \\
\hline Residual & 840 & 845.24 & 1.01 & & \\
\hline
\end{tabular}

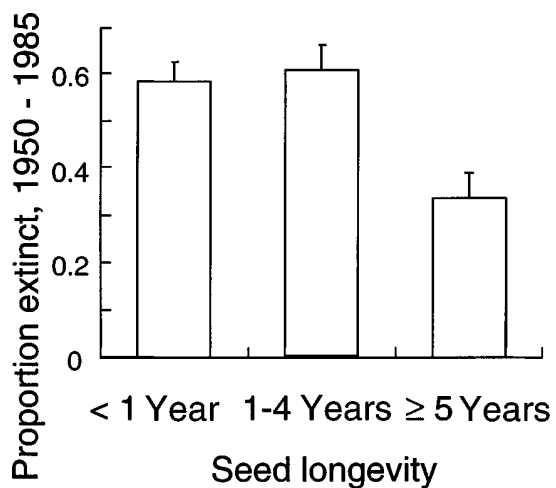

Fig. 1 Mean rate of extinctions from 1950 to 1985 in remnants of calcareous grasslands in three classes of seed longevity: $<1$ year comprises 81 species with a transient seed bank, 1-4 years 46 species with a short-term persistent seed bank, and $>5$ years 31 species with a long-term persistent seed bank. The relationship shown is significant at $\mathrm{P} \leq 0.001$ (analysis of deviance; Table 4). Error bars indicate $1 \mathrm{SE}$

with shorter-lived seeds. This relationship was confirmed by phylogenetically independent contrasts in seven genera. This supports our hypothesis that longer-lived seeds constitute a better buffer against risks of local extinction caused by stochastic processes than shorterlived seeds.

The integration of seed longevity into our analysis did not change our conclusions on the dependence of local extinction rates on Mesobromion specificity and on life form that we reported previously (Fischer and Stöcklin 1997). This result is not self-evident because different species properties are not independent of each other. As expected from other studies (Poschlod et al. 1996; Bekker et al. 1998; Davies and Waite 1998) species in our data set with higher Mesobromion specificity tended to have shorter-lived seeds. Nevertheless, habitat specificity proved to significantly affect extinction rates even though it was fitted after seed longevity. This indicates that specialist species are directly suffering from their isolation in calcareous grassland remnants, and that this conclusion was not based on an indirect effect of their lack of a persistent seed bank. This also holds for the vulnerable orchids whose seeds are never found in soil seed banks. In the North-West European flora shorterlived species (annuals and biennials) tend to have longerlived seeds (Thompson et al. 1998). This correlation is probably mostly due to species of highly disturbed habitats such as arable fields and ruderal sites. In contrast, the life span of species in our data set was independent of seed longevity. We conclude that life form, seed longevity, and Mesobromion specificity affected rates of local population extinction in calcareous grassland independently of each other.

Only 31 of the 158 study species have long-term persistent seeds. Compared with plant communities from more disturbed habitats this is a low proportion (Thompson et al. 1998). Hence, the potential to resist population extinction via seeds in the soil is comparatively small in species-rich calcareous grassland. This is particularly true for the most endangered species group of high Mesobromion specificity. Most of these species have transient seeds whereas longer-lived seeds are much more frequent in species with low or without Mesobromion specificity (Table 2). The regeneration of less habitat-specific species from seeds in the soil and their subsequent rapid occupation of space may even reduce the recolonization potential of characteristic Mesobromion species from source populations (Graham and Hutchings 1988; Hutchings and Booth 1996). Consequently, different seed longevity among different species groups may have contributed to the increase in the number of ubiquitous species which vulgarized the species composition from 1950 to 1985 (as reported in Fischer and Stöcklin 1997).

Local extinctions are taking place even in intact habitat remnants (such as nature reserves) and amongspecies patterns are in line with the hypothesis that stochastic processes are contributing to local extinctions. We conclude that seed longevity is important for population persistence and plant diversity in calcareous grassland. However, because most characteristic species of calcareous grassland lack a persistent seed bank they cannot rely on this buffering mechanism. Moreover, the recolonization potential of specialists from source pop- 
ulations may even be compromised by the regeneration potential of more ubiquitous species from their persistent seed banks.

Acknowledgements M.F. was supported by the Swiss National Science Foundation (Grant 31-49728.96). A list of study species, along with life form, habitat specificity, seed longevity, number of occurrences 1950 and 1985, and number of local extinctions, is available from J.S. upon request.

\section{References}

Bakker JP (1989) Nature management by grazing and cutting. Kluwer, Dordrecht

Bakker JP, Bos AF, Hoogveld J, Muller HJ (1991) The role of the seed bank in restoration management of semi-natural grasslands. In: Ravera $\mathrm{O}$ (ed) Terrestrial and aquatic ecosystems: perturbation and recovery. Ellis Horwood, New York, pp 449455

Bakker JP, Poschlod P, Strykstra RJ, Bekker RM, Thompson K (1996) Seed banks and seed dispersal: important topics in restoration ecology. Acta Bot Neerl 45:461-490

Bekker RM, Verweij GL, Smith REN, Reine R, Bakker JP, Schneider S (1997) Soil seed banks in European grasslands: does land use affect regeneration perspectives? J Appl Ecol 34:1293-1310

Bekker RM, Schaminée JHJ, Bakker JP, Thompson K (1998) Seed bank characteristics of Dutch plant communities. Acta Bot Neerl 47:15-26

Candy SG (1986) Fitting a parametric log-linear hazard function to grouped survival data. GLIM Newsl 13:28-31

Davies A, Waite S (1998) The persistence of calcareous grassland species in the soil seed bank under developing and established scrub. Plant Ecol 136:27-39

Ellstrand NC, Elam DR (1993) Population genetic consequences of small population size: implications for plant conservation. Annu Rev Ecol Syst 24:217-242

Fahrig L, Merriam G (1985) Habitat patch connectivity and population survival. Ecology 66:1762-1768

Fischer M, Stöcklin J (1997) Local extinctions of plants in remnants of extensively used calcareous grasslands 1950-1985. Conserv Biol 11:727-737

Graham DJ, Hutchings MJ (1988) A field investigation of germination from the seed bank of a chalk grassland ley on former arable land. J Appl Ecol 25:253-263

Groom MJ (1998) Allee effects limit population viability of an annual plant. Am Nat 151:487-496

Grubb PJ (1977) The maintenance of species richness in plant communities: the importance of the regeneration niche. Biol Rev 52:107-145

Harvey PH, Pagel MD (1991) The comparative method in evolutionary biology. Oxford University Press, Oxford

Harvey PH, Read AF, Nee S (1995) Why ecologists need to be phylogenetically challenged. J Ecol 83:535-536

Hutchings MJ, Booth KD (1996) Studies on the feasability of recreating chalk grassland vegetation on ex-arable land. I. The potential roles of the seed bank and the seed rain. J Appl Ecol 33:1171-1181

Landolt E (1977) Ökologische Zeigerwerte zur Schweizer Flora. Veröff Geobot Inst ETHZ 64:1-208

Leach MK, Givnish TJ (1996) Ecological determinants of species loss in remnant prairies. Science 273:1555-1558

Mazer SJ (1998) Alternative approaches to the analysis of comparative data: compare and contrast. Am J Bot 85:11941199
McCullagh P, Nelder JA (1989) Generalized linear models. Chapman Hall, London

Menges E (1990) Population viability analysis for an endangered plant. Conserv Biol 4:52-62

Menges ES (1991) The application of minimum viable population theory to plants. In: Falk DA, Holsinger KE (eds) Genetics and conservation of rare plants. Oxford University Press, Oxford, pp 45-61

Menges ES (1992) Stochastic modeling of extinction in plant populations. In: Fiedler PL, Jain SK (eds) Conservation biology: the theory and practice of nature conservation, preservation and management. Chapman Hall, New York, pp 253-275

Payne RW, Lane PW, Digby PGN, Harding SA, Leech PK, Morgan GW, Todd AD, Thompson R, Tunicliffe Wilson G, Welham SJ, White RP (1993) GENSTAT 5 reference manual. Clarendon Press, Oxford

Pimm SL, Jones HL, Diamond J (1988) On the risk of extinction. Am Nat 132:757-785

Poschlod P (1993) Die Dauerhaftigkeit von generativen Diasporenbaken in Böden am Beispiel von Kalkmagerrasenpflanzen und deren Bedeutung für den botanischen Arten- und Biotopschutz. Verh Ges Ökol 22:229-240

Poschlod P, Jackel A-K (1993) Untersuchungen zur Dynamik von generativen Diasporenbanken von Samenpflanzen in Kalkmagerrasen. Flora 188:49-71

Poschlod P, Fischer S, Kiefer S (1996) A coenotical approach of plant population viability analysis on successional and afforested calcareous grassland sites. In: Settele J, Margules CR, Poschlod P, Henle K (eds) Species survival in fragmented Landscapes. Kluwer, Dordrecht, pp 219-229

Ratcliffe DA (1984) Post-medieval and recent changes in British vegetation: the culmination of human influence. New Phytol 98:73-100

Shaffer ML (1987) Minimum viable populations: coping with uncertainty. In: Soulé ME (ed) Viable populations for conservation. Cambridge University Press, Cambridge, pp 69-86

Silvertown J, Franco M, Harper JL (1997) Plant life histories: ecology, phylogeny and evolution. Cambridge University Press, Cambridge

Simberloff D (1988) The contribution of population and community biology to conservation science. Annu Rev Ecol Syst 19:473-511

Thompson K (1992) The functional ecology of seed banks. In: Fenner M (ed) Seeds: the ecology of regeneration in plant communities. CAB International, Wallingford, pp 231-258

Thompson K (1993) Seed persistence in soil. In: Hendry GAF, Grime JP (eds) Methods in comparative plant ecology. Chapman Hall, London, pp 199-202

Thompson K, Grime JP (1979) Seasonal variation in the seed banks of herbaceous species in ten contrasting habitats. J Ecol 67:893-921

Thompson K, Bakker JP, Bekker RM (1997) Soil seed banks of North West Europe: methodology, density and longevity. University Press, Cambridge

Thompson K, Bakker JP, Bekker RM, Hodgson JG (1998) Ecological correlates of seed persistence in the soil in the north-west European flora. J Ecol 86:163-169

Tilman D (1997) Community invasibility, recruitment limitation, and grassland diversity. Ecology 78:81-92

Westoby M, Leishman MR, Lord JM (1995) On misinterpreting the "phylogenetic correction". J Ecol 83:531-534

Willems JH (1982) Phytosociological and geographical survey of Mesobromion communities in Western Europe. Vegetatio 48:227-240

Zoller H, Wagner C, Frey V (1986) Nutzungsbedingte Veränderungen in Mesobromion-Halbtrockenrasen in der Region Basel - Vergleich 1950-1985. Abh Westfälischen Mus Naturk 48:93-108 